\title{
Effect of Complexin II on Membrane Fusion between Liposomes Containing Mast Cell SNARE Proteins
}

\author{
Satoshi Tadokoro, ${ }^{*, a}$ Naohide Hirashima, ${ }^{b}$ and Naoko Utsunomiya-Tate ${ }^{a}$ \\ ${ }^{a}$ Faculty of Pharma Sciences, Teikyo University; 2-11-1 Kaga, Itabashi-ku, Tokyo 173-8605, Japan: and ${ }^{b}$ Graduate \\ School of Pharmaceutical Sciences, Nagoya City University; 3-1 Tanabe-dori, Mizuho-ku, Nagoya 467-8603, Japan. \\ Received October 2, 2015; accepted November 28, 2015
}

\begin{abstract}
Mast cells are involved in allergic responses and undergo exocytotic release of inflammatory mediators in response to antigen stimulation. Soluble $N$-ethylmaleimide-sensitive factor attachment protein receptor (SNARE) proteins are involved in this membrane fusion process; some SNARE-binding proteins regulate SNARE-dependent liposome membrane fusion. SNARE-binding protein complexin II is expressed in mast cells, where it positively regulates exocytotic release after antigen stimulation. We found that complexin II suppressed SNARE-dependent membrane fusion between mast cell SNARE-containing liposomes. This inhibitory effect of complexin II was abolished when we used a structurally divergent mutant (R59H) complexin II, where Arg59 is substituted with histidine. These results suggest that complexin II negatively regulates SNARE-dependent exocytotic membrane fusion in mast cells, and this inhibitory effect is dependent upon Arg59.
\end{abstract}

Key words mast cell; exocytosis; membrane fusion; soluble $N$-ethylmaleimide-sensitive factor attachment protein receptor (SNARE); degranulation

Mast cells are involved in allergic reactions. Cross-linking of FceRI, the high-affinity receptor for the Fc region of immunoglobulin E, by multivalent antigens increases intracellular $\mathrm{Ca}^{2+}$ concentration, causing exocytotic inflammatory mediator release from mast cells. ${ }^{1)}$ Soluble $N$-ethylmaleimide-sensitive factor attachment protein receptor (SNARE) proteins are involved in this process. $^{2-9)}$ SNARE-binding proteins also regulate exocytotic release in mast cells. ${ }^{9,10)}$

Syntaxin-3, -4 and synaptosomal-associated protein $23 \mathrm{kDa}$ (SNAP-23) are SNARE proteins on the plasma membrane (t-SNARE) in mast cells. ${ }^{2-4)}$ Vesicle associated membrane protein (VAMP)-2, -7 , and -8 are SNARE proteins on the secretory vesicles membrane (v-SNARE). ${ }^{3,4)}$ These t-SNARE and $\mathrm{v}$-SNARE interact with each other and form SNARE complex which induce exocytotic release. ${ }^{4-6)}$ Final stage of exocytosis is membrane fusion process between secretory granule membrane and plasma membrane. SNAP-23/syntaxin-3 or SANP23/syntaxin-4 incorporated liposomes fuse with VAMP-8 but not VAMP-7 incorporated liposomes. ${ }^{11)}$

Complexins possess an $\alpha$-helix in their central region that binds to and regulates SNAREs. ${ }^{12}$ Complexins I and II are expressed in neuronal cells and may be involved in neurotransmitter release. $^{13,14)}$ Complexin affects neuronal SNARE-mediated membrane fusion between liposomes. ${ }^{15,16)}$ Complexin II, but not complexin I, is expressed in mast cells, and exocytotic release after antigen stimulation is suppressed in mast cells where complexin II has been knocked down. ${ }^{10)}$ To elucidate the molecular mechanism of SNARE-dependent exocytosis in mast cells, we examined effects of complexin II on mast cell SNARE-dependent liposomal membrane fusion that is a simple assay system without other factors derived from cells. ${ }^{11,17-19)}$

\section{MATERIALS AND METHODS}

Protein Expression and Purification Full-length rat syntaxin-3, SNAP-23, VAMP-2 or -8, and complexin II were expressed in Escherichia coli (E. coli) and purified. ${ }^{11,18-20)}$ SNAP-23 was expressed as a glutathione $S$-transferase-tagged fusion protein. Syntaxin-3, VAMP-2 or -8 , and complexin II were expressed as histidine (His)-tagged fusion proteins. These proteins were purified by affinity chromatography. Proteins concentrations obtained were determined using the Bradford method.

Protein Reconstitution All lipids were obtained from Avanti Polar Lipids (Alabaster, AL, U.S.A.). VAMP-2 or -8 (v-SNARE) and SNAP-23/syntaxin-3 (t-SNARE) were reconstituted into liposomes. ${ }^{11,18-20)}$ For v-SNARE liposomes, $100-\mu \mathrm{L}$ VAMP solution $[1.5-\mathrm{mg} / \mathrm{mL}$ VAMP-2 or -8 , $0.8 \% \quad n$-octyl- $\beta$-D-glucoside, $100-\mathrm{mm} \mathrm{KCl}, 10 \%$ glycerol, 1-mm dithiothreitol (DTT), and 25-mm 4-(2-hydroxyethyl)1-piperazineethanesulfonic acid (HEPES)] was added to a 3-mm lipid film [1-palmitoyl-2-oleoyl-sn-glycero-3-phosphocholine (POPC) : 1,2-dioleoyl-sn-glycero-3-phospho-L-serine (DOPS) : 7-nitrobenz-2-oxa-1,3-diazol-4-yl (NBD)-1,2-dipalmitoyl-sn-glycero-3-phosphoethanolamine (DPPE):rhodamineDPPE in an $82: 15: 1.5: 1.5 \mathrm{M}$ ratio), and the lipid film was dissolved. Liposomes were prepared by detergent dilution and dialyzed against a reconstitution buffer (100-mM $\mathrm{KCl}, 10 \%$ glycerol, 1-mm DTT, and 25-mM HEPES) containing $1 \mathrm{~g} / \mathrm{L}$ of SM-2 Bio-Beads (Bio-Rad Laboratories, Hercules, CA, U.S.A.) overnight at $4^{\circ} \mathrm{C}$. Liposomes were separated by flotation in a Histodenz (Sigma-Aldrich, St. Louis, MO, U.S.A.) density gradient. v-SNARE liposomes were harvested from the $0 / 30 \%$ Histodenz interface. For t-SNARE liposomes, 500$\mu \mathrm{L}$ t-SNARE solution (4-mg/mL SNAP-23 and syntaxin-3, $0.8 \% n$-octyl- $\beta$-D-glucoside, $100-\mathrm{mm} \mathrm{KCl,} 10 \%$ glycerol, 1-mm DTT, and 25-mM HEPES) was added to a $15-\mathrm{mm}$ premixed lipid film (POPC:DOPS $=85: 15 \mathrm{M}$ ratio), and the lipid film was dissolved. Liposomes were prepared by detergent dilution, dialyzed against the reconstitution buffer, and harvested as described above. 
Membrane Fusion Assay Membrane fusion assays were performed. ${ }^{11,17-20)}$ All assays included $10-\mu \mathrm{L}$ v-SNARE and 90- $\mu \mathrm{L}$ t-SNARE liposomes with an additional $400-\mu \mathrm{L}$ reconstitution buffer or $20-\mu \mathrm{M}$ complexin II solution. t-SNARE liposomes were mixed with complexin II and incubated for $30 \mathrm{~min}$ at $4^{\circ} \mathrm{C}$. This mixture was added to v-SNARE liposomes, and NBD fluorescence was measured using a spectrofluorometer (FP-8300; Jasco, Tokyo, Japan) at $37^{\circ} \mathrm{C}$. Maximal NBD fluorescence intensity was determined by adding $100-\mu \mathrm{L}$ $2.5 \%$ Triton X-100. Membrane fusion was estimated. ${ }^{11,17-20)} \mathrm{V}$ SNARE and t-SNARE liposomes were mixed at time 0 , and fusion degree was estimated using the following formula:

$$
\text { Fusion degree }=100 \times[F(t)-F(0)] /\left[F_{\max }-F(0)\right]
$$

where $F(t)$ is NBD fluorescence intensity at $t, F(0)$ is the fluorescence intensity at $t=0$, and $F_{\max }$ is the maximal fluorescence intensity after adding $100-\mu \mathrm{L} 2.5 \%$ Triton X-100.

Circular Dichroism (CD) Analysis CD spectra were measured using a J-1500 Circular Dichroism Spectrometer (Jasco) in a cell with a 1-mm path-length. Each sample's concentration was $0.2-\mathrm{mg} / \mathrm{mL}$ in $40-\mathrm{mm}$ Tris $(\mathrm{pH} \mathrm{7.4)}$ and 100$\mathrm{mm} \mathrm{NaCl}$. Secondary structure components were estimated from CD spectra using the Jasco analytical program. ${ }^{21)}$

Statistical Analyses Data are presented as the mean standard error of the mean (S.E.M.), and statistical analyses were performed using Student's $t$-test or Kruskal-Wallis test with Bonferroni's correction for multiple comparison.

\section{RESULTS}

Fusion Degree between Mast Cell SNARE-Containing Liposomes Complexin II is expressed in mast cells where it positively regulates exocytotic release. ${ }^{10)}$ Complexin II also interacts with SNARE complexes containing SNAP-23, syntaxin-3, and VAMP-2 or -8 in mast cells. ${ }^{20)}$ We examined whether these SNARE proteins induce membrane fusion between liposomes. When we mixed VAMP-2 or -8 liposomes with SNAP-23/syntaxin-3 liposomes at $37^{\circ} \mathrm{C}$, membrane fusion occurred (Figs. 1A, B). However, SNAP-23/syntaxin-3/VAMP-2 combination induced membrane fusion more efficiently than SNAP-23/syntaxin-3/VAMP-8 combination (Fig. 1C). Membrane fusion does not occur between SNAP-23/syntaxin-3 liposomes and liposomes without VAMP. ${ }^{11)}$

Effects of Complexin II on SNARE-Mediated Liposome Fusion We investigated effects of complexin II on SNARE-mediated liposome fusion. The SNAP-23/syntaxin-3/ VAMP-2 combination efficiently induced membrane fusion (Fig. 1). Complexin suppresses neuronal SNARE-mediated membrane fusion in dose-dependent manner. ${ }^{15,16)}$ Scharb et al. revealed that $20 \mu \mathrm{M}$ Drosophila complexin inhibited neuronal SNARE-mediated membrane fusion by $c a .46 \%{ }^{15)}$ We examined effects of $20 \mu \mathrm{M}$ complexin II on membrane fusion between SNAP-23/syntaxin-3 and VAMP-2 liposomes. SNARE-mediated membrane fusion was inhibited in the presence of complexin II (Fig. 2). Mutant (R59H) complexin II, where Arg59 is replaced with His, exhibits decreased interaction with SNARE complexes in mast cells. ${ }^{20)}$ We examined effects of mutant (R59H) complexin II on SNARE-mediated liposome fusion. Mutant (R59H) complexin II had no statistically significant effect on SNARE-mediated membrane fusion
A

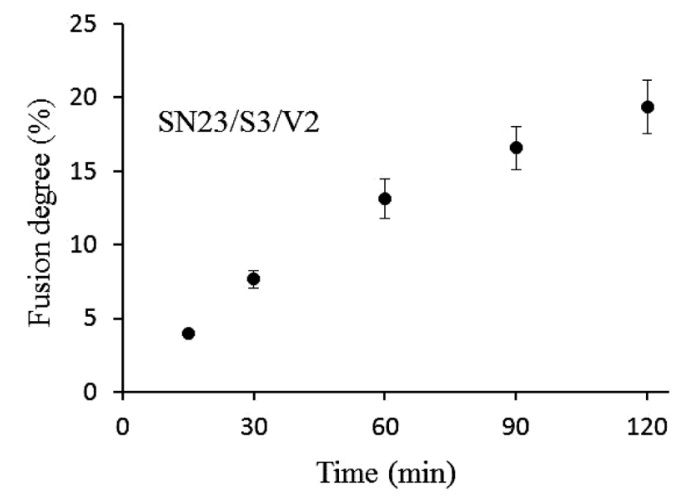

B

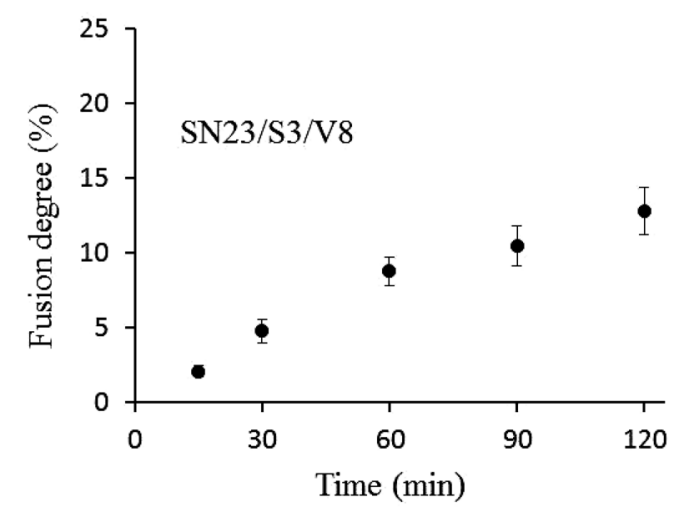

C

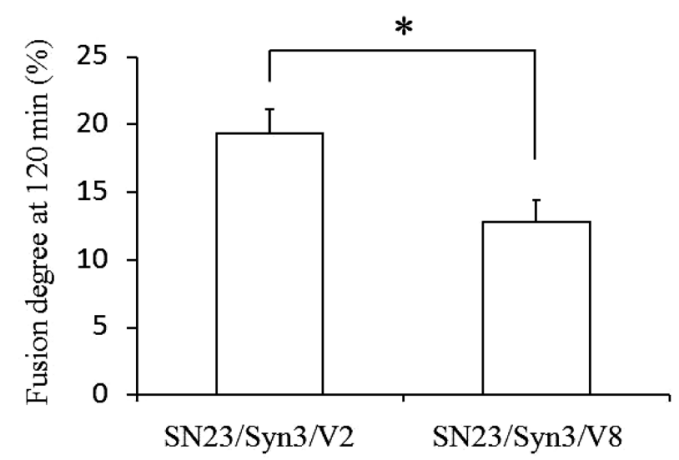

Fig. 1. Membrane Fusion between Mast Cell SNARE-Containing Liposomes

A. Time course of membrane fusion degree. SNAP-23/syntaxin-3 liposomes and VAMP-2 or -8 liposomes were mixed at time 0 at $37^{\circ} \mathrm{C}$. B. Values represent fusion extent at $120 \mathrm{~min}$. Data are represented as the mean \pm S.E.M. $(n=3, * p<0.05)$.

(Fig. 2). These results suggest that complexin II suppresses SNARE-mediated membrane fusion and Arg59 of complexin II is responsible for this inhibitory effect of complexin II.

Substitution of Arg59 with His Induces Secondary Structural Changes in Complexin II The Arg59 residue of complexin II is involved in its inhibitory effect on SNAREmediated membrane fusion in mast cells. We examined structural effects of Arg59 mutation on complexin II secondary 


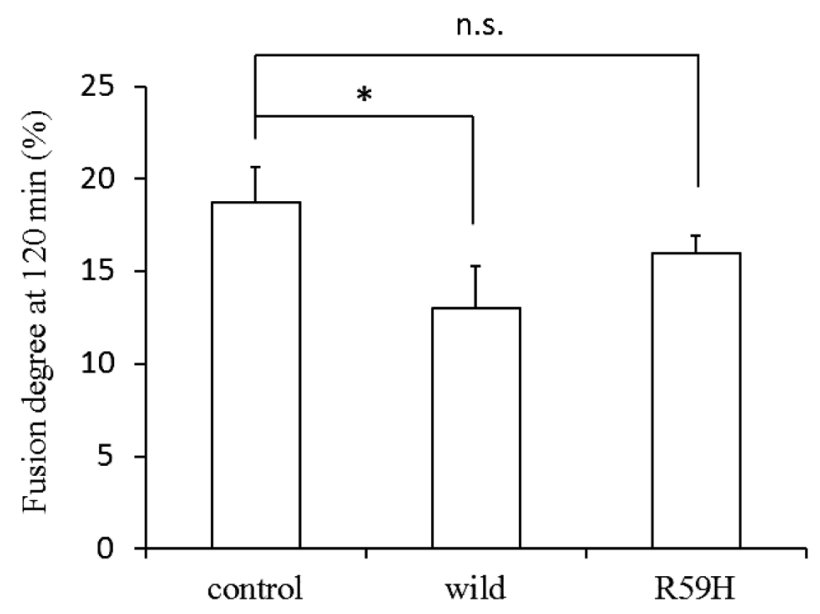

Fig. 2. Effect of Complexin II in SNARE-Mediated Liposome Fusion

Values represent fusion extent at $120 \mathrm{~min}$. Data are represented as the mean \pm S.E.M. $(n=5-6, * p<0.05$, Kruskal-Wallis test with Bonferroni's correction).

structure using CD spectroscopy. His-tagged wild-type and mutant $(\mathrm{R} 59 \mathrm{H})$ complexin II were expressed in E. coli and purified by affinity chromatography. Purified proteins were subjected to sodium dodecyl sulfate-polyacrylamide gel electrophoresis (SDS-PAGE) and stained using Coomassie brilliant blue. Wild-type and mutant (R59H) complexin II were successfully purified (Fig. 3A). Each proteins of the same concentration were subjected to CD spectroscopy. Substituting Arg59 with His induced changes in complexin II CD spectra (Fig. $3 \mathrm{~B})$. The contents of secondary structure of wild-type and mutant $(\mathrm{R} 59 \mathrm{H})$ complexin II are shown in Table 1.

\section{DISCUSSION}

We examined the role of complexin II on exocytosis-like membrane fusion in mast cells using a SNARE liposomebased fusion assay. ${ }^{11,17-20)}$ Complexin II suppressed mast cell SNARE-mediated membrane fusion (Fig. 2). Synaptotagmin 1 , a $\mathrm{Ca}^{2+}$ sensor for neuronal exocytosis, competes with complexin I for binding to neuronal SNARE complexes. It displaces complexin I from SNARE complexes in the presence of $\mathrm{Ca}^{2+}{ }^{22)}$ Complexin inhibits neuronal SNARE-mediated membrane fusion and that this inhibitory effect of complexin is abolished by $\mathrm{Ca}^{2+}$-synaptotagmin $1 .^{15,16)}$ These studies suggest that complexin exerts a clamp effect to block fusion until $\mathrm{Ca}^{2+}$ influx in response to stimulation. ${ }^{15,16,22)} \mathrm{Ca}^{2+}$-synaptotagmin 2 enhances mast cell SNARE-mediated liposome fusion. ${ }^{18,19)}$ Inhibitory effects of complexin II on mast cell SNAREmediated membrane fusion may also be abolished by $\mathrm{Ca}^{2+}$. synaptotagmin 2 . In the experimental system used in this study, there was no synaptotagmin $2 / \mathrm{Ca}^{2+}$ that is supposed to release complexin II from SNARE complex and triggers membrane fusion. Since complexin II is not released from SNARE complex, the inhibitory effect of complexin II is thought to be remained. On the other hand, we reported that knock-down of complexin II decreases exocytotic release in mast cells. ${ }^{10)}$ Complexin I binds to SNARE complex in nerve terminal and make it stable, ${ }^{23}$ therefore it is reasonable that SNARE complex become unstable in mast cells when complexin II is knocked down. We think that synaptotagmin 2 fails to bind to unstable SNARE complex, resulting in decrease of $\mathrm{Ca}^{2+}$ sensi-
A

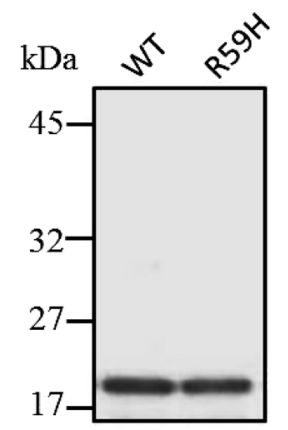

B

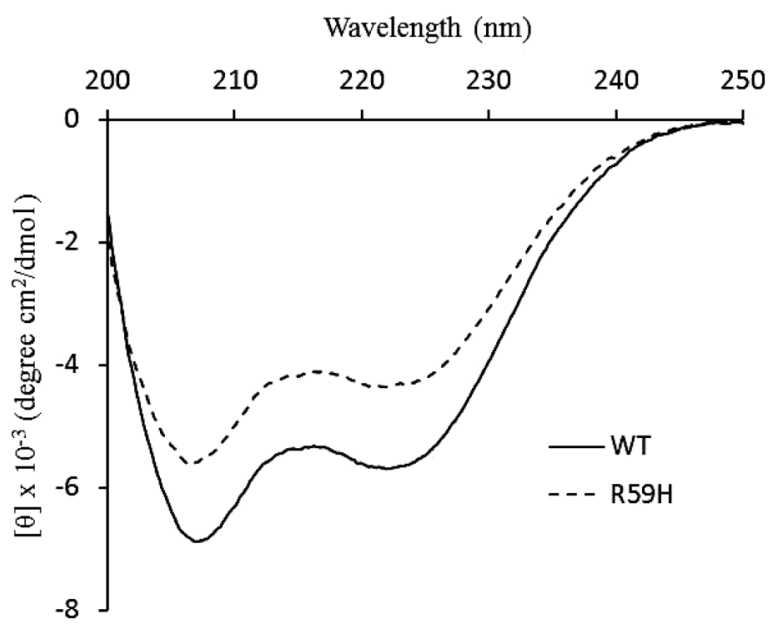

Fig. 3. Effect of Arg59 Substitution with His on Complexin II Secondary Structures

A. SDS-PAGE of wild-type and mutant (R59H) complexin II. B. CD spectra of wild-type and mutant $(\mathrm{R} 59 \mathrm{H})$ complexin II at $25^{\circ} \mathrm{C}$ in $40-\mathrm{mm}$ Tris $(\mathrm{pH} 7.4)$ and $100-\mathrm{mm} \mathrm{NaCl}$ are shown.

tivity and exocytotic release.

Mutant (R59H) complexin II had no statistically significant effect on mast cell SNARE-mediated membrane fusion (Fig. 2). Complexin I binds to neuronal SNARE complexes, and Arg59 residue of complexin I contributes to this crucial interaction. ${ }^{23)}$ Mutant (R59H) complexin I exhibits decreased binding to neuronal SNARE complexes. ${ }^{24)}$ Mutant (R59H) complexin II also exhibits reduced binding to SNARE complexes in mast cells. ${ }^{20)}$ Inhibitory effects of complexin II on SNAREmediated membrane fusion may depend on its interaction with SNARE complexes in mast cells.

We compared secondary structure of wild-type and mutant (R59H) complexin II and found that Arg59 substitution with His in complexin II reduced its $\alpha$-helix content (Fig. 3B, Table 1). Arginine and histidine are both basic amino acid but arginine is more basic than histidine due to their difference of $\mathrm{p} K_{\mathrm{a}}$ ( $\mathrm{p} K_{\mathrm{a}}$ of arginine and histidine are 12.5 and 7.6, respectively). Therefore, arginine has a net positive charge while histidine is partly protonated at the experimental condition ( $\mathrm{pH}$ 7.4). In addition, side-chain of arginine is straight but that of histidine is an imidazole ring and relatively bulky. These differences might affect the interaction with other amino acids, resulting in the reduction of $\alpha$-helix of complexin II. Complexins have 
Table 1. Contents of Secondary Structure of Wild-Type and Mutant (R59H) Complexin II

\begin{tabular}{lcc}
\hline \hline & WT & R59H \\
\hline$\alpha$-Helix (\%) & $58.7 \pm 1.7$ & $49.8 \pm 1.5^{* *}$ \\
$\beta$-Sheet (\%) & $9.4 \pm 2.9$ & $12.2 \pm 2.4$ \\
$\beta$-Turn (\%) & $0.0 \pm 0.0$ & $0.0 \pm 0.0$ \\
Random (\%) & $31.9 \pm 2.1$ & $38.0 \pm 1.3^{*}$ \\
\hline
\end{tabular}

Data are shown as the mean \pm S.E.M. $\left(n=7,{ }^{*} p<0.05,{ }^{*} p<0.01\right)$.

$\alpha$-helix in their central region (amino acids 48-70), involved in SNARE complex binding. ${ }^{12)}$ The reduction of $\alpha$-helix content should disrupt the ability of complexin II to bind to SNARE complexes. Therefore, mutant (R59H) complexin II might not exert significant effects on SNARE-mediated membrane fusion in mast cells.

Acknowledgment This work was partly supported by the Ministry of Education, Culture, Sports, Science and Technology of Japan (Grant 15K07033 to S.T.).

Conflict of Interest The authors declare no conflict of interest.

\section{REFERENCES}

1) Benhamou M, Blank U. Stimulus-secretion coupling by high-affinity $\operatorname{IgE}$ receptor: new developments. FEBS Lett., 584, 4941-4948 (2010).

2) Guo Z, Turner C, Castle D. Relocation of the t-SNARE SNAP-23 from lamellipodia-like cell surface projections regulates compound exocytosis in mast cells. Cell, 94, 537-548 (1998).

3) Hibi T, Hirashima N, Nakanishi M. Rat basophilic leukemia cells express syntaxin-3 and VAMP-7 in granule membranes. Biochem. Biophys. Res. Commun., 271, 36-41 (2000).

4) Paumet F, Mao JL, Martin S, Galli T, David B, Blank U, Roa M. Soluble NSF attachment protein receptors (SNAREs) in RBL-2H3 mast cells: functional role of syntaxin 4 in exocytosis and identification of a vesicle-associated membrane protein 8 containing secretory compartment. J. Immunol., 164, 5850-5857 (2000).

5) Puri N, Kruhlak MJ, Whiteheart SW, Roche PA. Mast cell degranulation requires $N$-ethylmaleimide-sensitive factor-mediated SNARE disassembly. J. Immunol., 171, 5345-5352 (2003).

6) Puri N, Roche PA. Ternary SNARE complexes are enriched in lipid rafts during mast cell exocytosis. Traffic, 11, 1482-1494 (2006).

7) Puri N, Roche PA. Mast cells possess distinct secretory granule subsets whose exocytosis is regulated by different SNARE isoforms. Proc. Natl. Acad. Sci. U.S.A., 105, 2580-2585 (2008).

8) Woska JR Jr, Gillespie ME. Small-interfering RNA-mediated identification and regulation of the ternary SNARE complex mediated
RBL-2H3 mast cell degranulation. Scand. J. Immunol., 73, 8-17 (2011).

9) Brochetta C, Suzuki R, Vita F, Soranzo MR, Claver J, Madjene LC, Attout T, Vitte J, Varin-Blank N, Zabucchi G, Rivera J, Blank U. Munc18-2 and syntaxin 3 control distinct essential steps in mast cell degranulation. J. Immunol., 192, 41-51 (2014).

10) Tadokoro S, Nakanishi M, Hirashima N. Complexin II facilitates exocytotic release in mast cells by enhancing $\mathrm{Ca}^{2+}$ sensitivity of the fusion process. J. Cell Sci., 118, 2239-2246 (2005).

11) Sakiyama H, Tadokoro S, Nakanishi M, Hirashima N. Membrane fusion between liposomes containing SNARE proteins involved in mast cell exocytosis. Inflamm. Res., 58, 139-142 (2009).

12) Rizo J, Rosenmund C. Synaptic vesicle fusion. Nat. Struct. Mol. Biol., 15, 665-674 (2008).

13) McMahon HT, Missler M, Li C, Südhof TC. Complexins: cytosolic proteins that regulate SNAP receptor function. Cell, 83, 111-119 (1995).

14) Reim K, Varoqueaux F, McMahon HT, Südhof TC, Brose N, Rosenmund $\mathrm{C}$. Complexins regulate a late step in $\mathrm{Ca}^{2+}$-dependent neurotransmitter release. Cell, 104, 71-81 (2001).

15) Schaub JR, Lu X, Doneske B, Shin YK, McNew JA. Hemifusion arrest by complexin is relieved by $\mathrm{Ca}^{2+}$-synaptotagmin I. Nat. Struct. Mol. Biol., 8, 748-750 (2006).

16) Chicka MC, Chapman ER. Concurrent binding of complexin and synaptotagmin to liposome-embedded SNARE complexes. Biochemistry, 48, 657-659 (2009).

17) Weber T, Zemelman BV, McNew JA, Westermann B, Gmachl M, Parlati F, Söllner TH, Rothman JE. SNAREpins: minimal machinery for membrane fusion. Cell, 92, 759-772 (1998).

18) Nagai Y, Tadokoro S, Sakiyama H, Hirashima N. Effects of synaptotagmin 2 on membrane fusion between liposomes that contain SNAREs involved in exocytosis in mast cells. Biochim. Biophys. Acta, 1808, 2435-2439 (2011).

19) Tadokoro S, Inoh Y, Nakanishi M, Hirashima N. Effect of PIP2 on membrane fusion between mast cell SNARE liposomes mediated by synaptotagmin 2. Biochim. Biophys. Acta, 1848 (10 Pt A), 2290-2294 (2015).

20) Tadokoro S, Nakanishi M, Hirashima N. Complexin II regulates degranulation by interacting with SNARE complex containing syntaxin-3 in RBL-2H3 cells. Cell. Immunol., 261, 51-56 (2010).

21) Reed J, Reed TA. A set of constructed type spectra for the practical estimation of peptide secondary structure from circular dichroism. Anal. Biochem., 254, 36-40 (1997).

22) Tang J, Maximov A, Shin OH, Dai H, Rizo J, Südhof TC. A complexin/synaptotagmin 1 switch controls fast synaptic vesicle exocytosis. Cell, 126, 1175-1187 (2006).

23) Chen X, Tomchick DR, Kovrigin E, Araç D, Machius M, Südhof TC, Rizo J. Three-dimensional structure of the complexin/SNARE complex. Neuron, 33, 397-409 (2002).

24) Xue M, Reim K, Chen X, Chao HT, Deng H, Rizo J, Brose N, Rosenmund C. Distinct domains of complexin I differentially regulate neurotransmitter release. Nat. Struct. Mol. Biol., 10, 949-958 (2007). 